\title{
LA INCONSISTENCIA DEL FUNDAMENTO CONSTITUCIONAL DE LA ELIMINACIÓN DE LA POSIBILIDAD DE RESTRICCIÓN JUDICIAL DEL SUFRAGIO POR CAUSA DE DISCAPACIDAD MENTAL
}

\author{
The inconsistency of the constitutional foundation of the \\ elimination of the possibility of judicial restriction of \\ the suffrage by cause of mental disability
}

\author{
LUIS A. GÁLVEZ MUÑOZ \\ Universidad de Murcia \\ lgalvez@um.es
}

Cómo citar/Citation

Gálvez Muñoz, L. A. (2021).

La inconsistencia del fundamento constitucional de la eliminación de la posibilidad de restricción judicial del sufragio por causa de discapacidad mental. Revista Española de Derecho Constitucional, 121, 45-72. doi: https://doi.org/10.18042/cepc/redc.121.02

\section{Resumen}

La eliminación de la posibilidad de restringir el ejercicio del derecho de sufragio a las personas sometidas a un proceso de modificación de capacidad o de autorización de internamiento psiquiátrico que ha realizado la ley de reforma del régimen electoral general de diciembre de 2018 (Ley Orgánica 2/2018, de 5 de diciembre, de reforma de la Ley Orgánica 5/1985, de 19 de junio) se apoya en una concreta fundamentación constitucional que, a juicio del autor, carece de consistencia jurídica. A explicarlo se dedica este artículo, en el que se desmontan paso a paso los argumentos esgrimidos sobre violación de los principios fundamentales de sufragio universal, igualdad ante la ley y no discriminación y protección de las personas con discapacidad, exponiendo su significado preciso y por qué no resultan comprometidos en el caso. 
Palabras clave

Derecho de sufragio; elecciones; sufragio universal; igualdad; discriminación; discapacidad.

\begin{abstract}
The elimination of the possibility of restricting the exercise of the right of suffrage to people sometimes a process of capacity modification or authorization of psychiatric internment that has been carried out by the law of reform of the general electoral regime of December 2018 (Organic Law 2 / 2018, of December 5, of reform of the Organic Law 5/1985, of June 19) is based on a concrete constitutional foundation that, a trial of the author, lacks legal consistency. This article is dedicated to explaining this, in which the arguments put forward in violation of the fundamental principles of universal suffrage, equality before the law and non-discrimination and protection of persons with disabilities are taken apart step by step, stating their precise meaning and why Not engaged in the case.
\end{abstract}

\title{
Keywords
}

Right to vote; elections; universal suffrage; equality; discrimination; disability. 


\section{SUMARIO}

I. INTRODUCCIÓN. II. NO SE VULNERA EL PRINCIPIO DE UNIVERSALIDAD DEL SUFRAGIO: 1. La capacidad de intervención legislativa en el derecho de sufragio. 2. La autodeterminación política como presupuesto de la universalidad del sufragio. III. NO SE LESIONA EL PRINCIPIO DE IGUALDAD Y NO DISCRIMINACIÓN: 1. No es una medida esencialmente discriminatoria. 2. No es una medida desproporcionada. IV. NO EXISTE INCOMPATIBILIDAD CON EL SISTEMA DE PROTECCIÓN DE LAS PERSONAS CON DISCAPACIDAD. BIBLIOGRAFÍA.

\section{INTRODUCCIÓN}

La eliminación de la posibilidad de privar del ejercicio del sufragio, por falta de capacidad electoral, a las personas sometidas a un proceso de modificación de capacidad o de autorización de internamiento psiquiátrico ha sido el motor y el objeto fundamental de la Ley Orgánica 2/2018, de 5 de diciembre, de reforma de la Ley Orgánica 5/1985, de 19 de junio, del Régimen Electoral General (LOREG), para garantizar el derecho de sufragio de todas las personas con discapacidad. En particular, se ha suprimido la prescripción del art. 3.1, apdos. b) y c), de que carecen de derecho de sufragio «los declarados incapaces en virtud de sentencia judicial firme, siempre que la misma declare expresamente la incapacidad para el ejercicio del derecho de sufragio», $\mathrm{y}$ «los internados en un hospital psiquiátrico con autorización judicial, durante el período que dure su internamiento siempre que en la autorización el juez declare expresamente la incapacidad para el ejercicio del derecho de sufragio», así como el mandato complementario del art. 3.2 de que «los Jueces o Tribunales que entiendan de los procedimientos de incapacitación o internamiento deberán pronunciarse expresamente sobre la incapacidad para el ejercicio del sufragio y que en el supuesto de que ésta sea apreciada, lo comunicaran al Registro Civil para que se proceda a la anotación correspondiente».

1 La Ley Orgánica 2/2018, de 5 de diciembre, ha introducido otras dos importantes modificaciones en la LOREG. En primer lugar, ha establecido en el apdo. 3.2 una prescripción general sobre el ejercicio del derecho de sufragio: «Toda persona podrá ejercer su derecho de sufragio activo, consciente, libre y voluntariamente, cualquiera que sea su 
Esta supresión tiene como base una concreta y variada argumentación material, que han elaborado la doctrina ${ }^{2}$ y diversos organismos internacionales en los últimos años ${ }^{3}$ y que ha sido recogida y utilizada con profusión en su lucha por las asociaciones de personas con discapacidad. En este sentido se considera que la norma en cuestión lesiona importantes principios constitucionales conectados con derechos fundamentales y que deben ser leídos a la luz de la Convención Internacional de Derechos de las Personas con Discapacidad, aprobada en Nueva York el 13 de diciembre de 2006. Así, el principio de universalidad del sufragio previsto en el art. 23.1 de la CE, donde se reconoce este derecho a todos «los ciudadanos», sin preverse excepción alguna o llamadas al legislador, lo que impediría su restricción a una parte de la ciudadanía; el principio de igualdad ante la ley y no discriminación por determinadas circunstancias, entre las que cabe incluir la discapacidad, reconocido en el art. 14 de la CE, que impediría que determinadas personas con discapacidad puedan ser sometidas a una evaluación de su capacidad para ejercer un derecho que no se exige al resto de los ciudadanos, y el principio de protección y favorecimiento de las personas con discapacidad consagrado en el art. $49 \mathrm{de}$ la $\mathrm{CE}$, que exige a los poderes públicos ampararles en el disfrute de sus derechos, como el de participación, lo que haría inviable su limitación.

Han existido otros argumentos, de carácter más formal, como el de la exigibilidad internacional de esta en virtud de la aprobación de la Convención Internacional de Derechos de las Personas con Discapacidad de 2006 —en especial, su art. 29- o el de la tendencia comparada igualatoria imperante y en progresión en materia de discapacidad, pero no tienen, obviamente, la

forma de comunicarlo y con los medios de apoyo que requiera». Y, en segundo término, ha añadido a la LOREG una nueva disposición adicional, la octava, relativa al reintegro del derecho de sufragio de todas aquellas personas que en el momento de entrada en vigor de la reforma lo tuvieran suprimido: «A partir de la entrada en vigor de la Ley de modificación de la Ley Orgánica del Régimen Electoral General para adaptarla a la Convención Internacional sobre los Derechos de las Personas con Discapacidad, quedan sin efecto las limitaciones en el ejercicio del derecho de sufragio establecidas por resolución judicial fundamentadas jurídicamente en el apartado 3.1. b) y c) de la Ley Orgánica 5/1985, de 19 de junio, ahora suprimidas. Las personas a las que se les hubiere limitado o anulado su derecho de sufragio por razón de discapacidad quedan reintegradas plenamente en el mismo por ministerio de la ley».

2 Entre otros autores, véanse Martínez-Pujalte (2015: 86 y ss.), Cuenca Gómez (2018) y Beckman (2009).

3 Como el Comité de Derechos de las Personas con Discapacidad, la Oficina del Alto Comisionado de Naciones Unidas para los Derechos Humanos, el Comité Económico y Social de la Unión Europea o la Agencia Europea de Derechos Fundamentales. 
misma fuerza. Ha sido realmente la fundamentación material citada lo que ha llevado a nuestro país, como a otros muchos Estados, a decidirse por reformar su legislación en este sentido.

No, sin embargo, esta crítica al art. 3 de la LOREG, en la redacción anterior a la reforma, por mucha vehemencia que sus propagadores hayan puesto en ella ${ }^{4}$, pues ninguno de los argumentos sostenidos en su articulación nos parece consistente, y es a explicarlo a lo que se dedica la presente contribución. Veámoslo paso a paso.

\section{NO SE VULNERA EL PRINCIPIO DE UNIVERSALIDAD DEL SUFRAGIO}

En primer lugar, el anterior art. 3 de la LOREG no lesiona, a nuestro juicio, el principio de sufragio universal proclamado en el art. 23.1 de la CE y que se conecta con la expresión "ciudadanos", con la que se reconoce el derecho de sufragio 5 . No cabe llegar a esta conclusión si tenemos en cuenta la capacidad de intervención del legislador en el ámbito del derecho de sufragio y el propio significado del principio de sufragio universal que presupone la capacidad de autodeterminación política.

\section{LA CAPACIDAD DE INTERVENCIÓN LEGISLATIVA EN EL DERECHO DE SUFRAGIO}

Ante todo, de los términos del art. 23.1 de la CE al reconocer el derecho de sufragio no se deduce incompatibilidad alguna con el anterior art. 3 de la LOREG. Es cierto que el art. 23.1 de la CE atribuye el derecho de sufragio

4 A este respecto tiene gran interés conocer el debate parlamentario producido durante la tramitación de la iniciativa. Véanse Fernández Esquer (2019: 219 y ss.) y Arnaldo Alcubilla (2019a: 29 y ss.; 2019b: 87 y ss.).

5 En sentido contrario, véase, entre otros, Cuenca Gómez (2018: 185-186). Por lo demás, esta crítica fue uno de los elementos fundamentales de los diferentes recursos que dieron lugar al ATC 196/2016, de 28 de noviembre, que confirmó la inadmisión de un recurso de amparo en el que se cuestionaba la constitucionalidad del art. 3 de la LOREG. Así, del recurso de nulidad de actuaciones presentado por la Fiscalía General del Tribunal Supremo contra la Sentencia del Tribunal Supremo de 17 de marzo de 2016 confirmatorio de la sentencia que denegaba el ejercicio del sufragio a determinada persona, del recurso de amparo contra esta sentencia interpuesto por los representantes de la persona a la que se le había restringido dicho derecho de sufragio y del posterior recurso de súplica del Ministerio Fiscal contra su inadmisión por providencia de la Sección Tercera del Tribunal Constitucional. 
activo a los ciudadanos en general, sin establecer limitación o excepción alguna o llamadas al legislador ${ }^{6}$, pero de este solo dato no cabe extraer la lesión del derecho por dicho art. 3 de la $\mathrm{LOREG}^{7}$, pues hay que tener en cuenta que la expresión "ciudadanos» no ha sido objeto de definición constitucional alguna y no hay razones para identificarla de forma automática con otras expresiones constitucionales más precisas, como «toda persona» $\mathrm{o}$ "los españoles», ni tampoco con la condición de reunir la mayoría de edad ${ }^{8}$.

Muy al contrario. El derecho de sufragio es un derecho de configuración legal ${ }^{9}$ y, en cuanto tal, la determinación de sus elementos estructurales, incluidas las condiciones que afectan a la titularidad y ejercicio, como ha reconocido de forma expresa el Tribunal Constitucional en varias ocasiones ${ }^{10}$, corresponde al legislador. Este dispone de cierto margen de actuación, siempre, naturalmente, que persiga un fin legítimo, no menoscabe su contenido esencial y respete los demás derechos y principios constitucionales (como la igualdad y no discriminación o la protección y promoción de colectivos específicos), de acuerdo con el principio de proporcionalidad, requisitos que - como podremos comprobar en este apartado y los siguientes- se cumplían en el caso del art. 3 de la LOREG.

Y así lo volvió a señalar el Tribunal Constitucional en el controvertido Auto 196/2016, de 28 de diciembre, que cerró el paso al estudio en profundidad por el Tribunal de la constitucionalidad del derogado art. 3 de la LOREG. En él se dice sobre la cuestión ahora abordada en conexión con este artículo lo siguiente:

Hemos de recordar, sin embargo, que el derecho de sufragio activo universal es un derecho fundamental de configuración legal (arts. 68.1 CE, respecto del Congreso, 69.2 CE, del Senado, 140 en relación con los ayuntamientos y 152 en relación con las Asambleas Legislativas de las Comunidades Autónomas)

6 El art. 23.1 de la CE literalmente seńala que «los ciudadanos tienen el derecho a participar en los asuntos públicos, directamente o por medio de representantes, libremente elegidos en elecciones periódicas por sufragio universal».

7 Sobre el concepto de ciudadano y su conexión con la titularidad de los derechos de participación, véanse Aláez Corral (2006) y Pérez Alberdi (2013: 72 y ss.).

8 La Constitución la emplea en diecinueve ocasiones, sin definirla en ninguna. No obstante, en la mayoría de los casos es evidente su equivalencia con la expresión «toda persona».

9 Sobre esta dimensión del derecho de sufragio, véase Solozábal Echavarría (2004: 130). Véanse también Azpitarte Sánchez (2002: 425 y ss.) y Pérez Alberdi (2013: 109 y ss.).

10 Así, STC 153/2014, de 25 de noviembre, FF. JJ. tercero y cuarto. 
como ha señalado expresamente la STC 153/2014, de 25 de septiembre, FJ 3, según la cual «la participación ha de sustanciarse en los términos en que el precepto haya sido desarrollado por el legislador electoral (arts. 53.1 y $81.1 \mathrm{CE}$ ), siempre que dicho desarrollo no menoscabe el contenido esencial del derecho fundamental ni infrinja los preceptos constitucionales».

No es ya que no existe una definición constitucional de "ciudadano» (art. 23.1 $\mathrm{CE})$, ni sería posible constitucionalmente restringir esta noción a los mayores de dieciocho años (art. $12 \mathrm{CE}$ ), sino que tampoco, desde este mismo punto de vista constitucional, se identifica ese concepto con el de nacionalidad o vecindad, pues, como resaltó la citada Sentencia «la determinación de las condiciones que afectan a la titularidad y ejercicio del derecho de sufragio se sitúan en el dominio del legislador electoral» (STC 153/2014, de 25 de septiembre, FJ 7).

Los arts. 2 y 3 LOREG condicionan el ejercicio del derecho de sufragio activo, además de a la nacionalidad —exigencia que tampoco es absoluta—, a la mayoría de edad, a la inscripción en el censo electoral, así como a la ausencia de alguna de las circunstancias previstas en el artículo 3, entre las que se encuentra la privación judicial en procesos de incapacitación o de internamiento por razón de trastorno psíquico. De ese modo, el modelo constitucional de sufragio universal no es per se incompatible con la privación singularizada de este derecho, por causa legalmente prevista, sobre todo cuando dicha privación está revestida de la garantía judicial ${ }^{11}$.

Esta posición encuentra apoyo, por otra parte, en el derecho internacional de los derechos humanos, canon de interpretación de gran valor en virtud de la llamada a este que hace el art. 10.2 de la CE. Los elementos más relevantes que considerar son los siguientes:

a) La Declaración Universal de Derechos Humanos, de 10 de diciembre de 1948, no contiene ninguna cláusula limitativa cuando proclama los derechos de participación ${ }^{12}$, pero sí la establece de forma general para todos los derechos que reconoce. Lo hace en el art. 29.2, que dispone que en el ejercicio de sus derechos y en el disfrute de sus libertades "toda persona estará solamente sujeta a las limitaciones establecidas por la ley con el único fin de asegurar el reconocimiento y el respeto de los derechos y libertades de los demás, y de satisfacer las justas exigencias de la moral, del orden público y del bienestar general en una sociedad democrática».

1 FJ segundo.

12 Véase el art. 21 de la Declaración Universal de Derechos Humanos, de 10 de diciembre de 1948, dedicado a proclamar los derechos de participación, elecciones libres y acceso a la función pública. 
b) El art. 25 del Pacto Internacional de Derechos Civiles y Políticos de 1996 sí la establece, en cambio, de forma específica. Al reconocer los derechos políticos —entre ellos el derecho de «todos los ciudadanos [...] a votar y ser elegidos en elecciones periódicas, auténticas, realizadas por sufragio universal e igual y por voto secreto que garantice la libre expresión de la voluntad de los electores» — introduce la apostilla «sin restricciones indebidas».

El Comité de Derechos Humanos de Naciones Unidas ha precisado en su observación general 25, de 1996, el alcance de este art. 25, señalando que «el ejercicio de estos derechos por los ciudadanos no puede suspenderse ni negarse, salvo por los motivos previstos en la legislación y que sean razonables y objetivos", y cita como ejemplo que "la incapacidad mental verificada puede ser motivo para negar a una persona el derecho a votar o a ocupar un cargo público» ${ }^{13}$. El Comité ha reiterado en 2013 la vigencia de esta observación ${ }^{14}$.

c) El Convenio Europeo de Derechos Humanos de 1950 no contiene ni una cláusula limitativa general para los derechos que proclama, ni específica para el derecho a las elecciones libres reconocido en el protocolo adicional de 1952, pero el Tribunal Europeo de Derechos Humanos sí ha admitido en varias ocasiones la conformidad al Convenio de la delimitación por el legislador del ámbito subjetivo del derecho de sufragio ${ }^{15}$. Y lo ha hecho de forma específica para las personas con discapacidad mental en el caso Alajos Kiss contra Hungría, de 2010, al señalar que los derechos reconocidos en el art. 3 del protocolo número 1 al Convenio «no son absolutos» y que «queda espacio para limitaciones implícitas», que "hay que conceder un mayor margen de apreciación a los Estados miembros en este campo", si bien deben cumplirse las reglas establecidas por el Tribunal para la limitación de derechos y tener en cuenta que, en caso de restricción de derechos a un colectivo vulnerable, como sucede con las personas con discapacidad mental, «el margen de apreciación del Estado es sustancialmente más estrecho» y debe aplicarse un escrutinio riguroso ${ }^{16}$.

13 Fue aprobada por el Comité de Derechos Humanos de Naciones Unidas el 12 de julio de 1996, en su 57. período de sesiones.

14 Véanse las observaciones finales Comité de Derechos Humanos de Naciones Unidas sobre la situación de los derechos civiles y políticos en Belice, punto 24, aprobadas el 26 de marzo de 2013, en su 107. ${ }^{\circ}$ período de sesiones (CCPR/C/BLZ/CO/1).

15 Así, véanse, entre otras muchas sentencias del Tribunal Europeo de Derechos Humanos, las de Mathieu-Mohin y Clerfayt contra Bélgica, de 2 de marzo de 1987; Aziz contra Chipre, de 22 de junio de 2004, o Hirst contra el Reino Unido, de 6 de octubre de 2005.

16 Tribunal Europeo de Derechos Humanos, Sentencia Alajos Kiss contra Hungría, de 20 de mayo de 2010, puntos 38 a 44. Su doctrina fue reiterada en 2014 en relación 
No es obstáculo a este estado de cosas en el ámbito internacional el art. 29 de la Convención de Derechos de las Personas con Discapacidad de 2006, relativo a la participación política y pública de las personas con discapacidad. Este precepto, a nuestro juicio, y a diferencia de lo que señalan el Comité de Derechos de las Personas con Discapacidad ${ }^{17}$ y numerosos autores ${ }^{18}$, no consagra un derecho incondicional al ejercicio del sufragio de toda persona con discapacidad, de tal forma que no quepa admitir excepción alguna a este, cualquiera que sea el estado de conciencia o grado de discapacidad mental de la persona ${ }^{19}$.

El art. 29 no se expresa en estos términos, ni tampoco formula ninguna prohibición expresa de limitar su ejercicio en todo supuesto. Establece, ciertamente, la obligación de los Estados partes de asegurar que las personas con discapacidad puedan participar plena y efectivamente en la vida política y pública en igualdad de condiciones con las demás, incluyendo «el derecho y la posibilidad de las personas con discapacidad a votar", pero no impone esta obligación de forma aislada, sino a través de una serie de «formas» como la accesibilidad de los procedimientos, instalaciones y materiales, la protección del secreto del voto o posibilidad de voto asistido ${ }^{20}$. Su finalidad no es, por

con otras dos demandas más contra Hungría: casos Gajesi y Harmati, resueltos, respectivamente, por sentencias de 23 de septiembre de 2014 y de 21 de octubre de 2014.

17 El Comité lo ha sostenido así de forma reiterada. Véanse, por ejemplo, las observaciones finales, aprobadas el 23 de septiembre de 2011, al informe presentado por España con arreglo al art. 35 de la Convención, su Dictamen de 9 de septiembre de 2013 sobre la Comunicación 4/2011 presentada por varias personas con discapacidad de nacionalidad húngara (CRPD/C/10/D/4/2011), y la Observación General n. ${ }^{\circ}$ 6, de 2018, sobre la igualdad y la no discriminación consagradas en el art. 5 de la Convención.

18 Véanse, entre otros, Martínez-Pujalte (2015: 91-92), Pascual Planchuelo (2016) y Rivas Vañó (2018: 276-279).

19 En este sentido, véanse Barrat Esteve (2017: 159) y Vyhnánek (2010: 121).

20 El dictado literal que emplea el art. 29, en la parte que nos interesa, es el siguiente: «Los Estados Partes garantizarán a las personas con discapacidad los derechos políticos y la posibilidad de gozar de ellos en igualdad de condiciones con las demás y se comprometerán a:

a) Asegurar que las personas con discapacidad puedan participar plena y efectivamente en la vida política y pública en igualdad de condiciones con las demás, directamente o a través de representantes libremente elegidos, incluidos el derecho y la posibilidad de las personas con discapacidad a votar y ser elegidas, entre otras formas mediante: 
tanto, imponer a los Estados un reconocimiento pleno y absoluto, sin excepciones, de la integridad del derecho de sufragio de todas las personas con discapacidad, sino, más bien, implicarlos en una tarea precisa de remoción de obstáculos y de apoyos para conseguir la participación de las personas con discapacidad en condiciones de igualdad.

Y así lo vio también el Tribunal Constitucional, zanjando las dudas interpretativas sobre el alcance del precepto y su posible incompatibilidad con el anterior art. 3 de la LOREG. En el auto ya citado de 2016 señala que la discapacidad en el sentido de la Convención «es un concepto muy amplio en que tiene cabida cualquier "deficiencia física, mental, intelectual o sensorial a largo plazo" que pueda impedir la efectiva igualdad», y que su "finalidad se inscribe más bien, en línea con el mandato contenido en el art. 9.2 CE, de remover los obstáculos que impidan o dificulten la emisión del voto libre, secreto y sin intimidación [apartado a, II y II, del art. 29; (sic)] de las personas con discapacidad $\aleph^{21}$.

\section{LA AUTODETERMINACIÓN POLITICA COMO PRESUPUESTO DE LA UNIVERSALIDAD DEL SUFRAGIO}

No es esto, sin embargo, todo lo que cabe decir en favor de la compatibilidad del precedente art. 3 de la LOREG con el principio de universalidad del sufragio, pues cabe aportar otro relevante argumento, aunque estrechamente conectado con el anterior, por incidir ambos en la naturaleza y esencia de este derecho. Nos referimos al correcto entendimiento del principio de universalidad del sufragio ${ }^{22}$.

i) La garantía de que los procedimientos, instalaciones y materiales electorales sean adecuados, accesibles y fáciles de entender y utilizar;

ii) La protección del derecho de las personas con discapacidad a emitir su voto en secreto en elecciones y referéndum públicos sin intimidación, y a presentarse efectivamente como candidatas en las elecciones, ejercer cargos y desempeñar cualquier función pública a todos los niveles de gobierno, facilitando el uso de nuevas tecnologías y tecnologías de apoyo cuando proceda;

iii) La garantía de la libre expresión de la voluntad de las personas con discapacidad como electores y a este fin, cuando sea necesario y a petición de ellas, permitir que una persona de su elección les preste asistencia para votar».

21 ATC 196/2016, de 28 de noviembre, FJ tercero.

22 Sobre el principio de sufragio universal, véase, en general, Gálvez Muñoz (2014: 171 y ss.). Véase, también, Presno Linera (2003: 103 y ss.). 
Se trata de advertir que el sufragio universal opera y se afirma propiamente no en relación con toda persona, sino respecto de quienes formen parte de la comunidad política de que se trate y dispongan, además — por lo que ahora nos interesa-, de la capacidad de autodeterminación política o electoral, es decir, de las facultades mínimas precisas para poder formar una voluntad electoral consciente y libre, de la posibilidad de comprender la naturaleza y el acto de votar y poder determinar una voluntad electoral.

Esto nos remite a la misma delimitación del derecho de sufragio, que, como parte de su núcleo esencial, demanda esta capacidad de autodeterminación política en su ejercicio. Esta es un presupuesto indispensable de la participación política, que ha de ser necesariamente consciente y libre para poder ser auténtica. La capacidad de autodeterminación política es, pues, un elemento básico de la configuración del derecho de sufragio, que resulta de su misma delimitación. Es, más que un límite al derecho de sufragio en sentido propio, un elemento interno al propio derecho, que contribuye a definirlo constitutivamente.

En este sentido ya apuntó Kelsen (1934: 34), hace casi un siglo, que existen ciertos "límites naturales» que «se oponen a la generalización de los derechos políticos y restringen el pueblo en el sentido activo", citando expresamente "la capacidad mental», además de la edad y la capacidad moral. Y, entre nosotros, y más recientemente, Presno Linera (2003: 135-136) ha señalado que «la capacidad de autodeterminación política, fruto de la posibilidad de comprender las diferentes opciones y de discriminar entre ellas las que se consideren preferibles para la orientación de la comunidad, es, pues, una exigencia inherente a la participación y, por este motivo, su ausencia es un límite lógico de este derecho» ${ }^{23}$.

23 Presno Linera (2003: 135-136, y 144; también en 2011: 33 y ss.) se ocupa de esta cuestión con mayor detalle, conectando la minoría de edad con la alteración de capacidad de los mayores:

«La exigencia de una edad mínima tiene una relación directa con la configuración del sufragio como instrumento al servicio de la participación política; ésta requiere la capacidad para autodeterminarse, para intervenir en la formación de las diferentes opciones políticas y para poder pronunciarse sobre ellas, lo que únicamente puede hacerse si se cuenta con la capacidad suficiente para discernir entre unas y otras propuestas.

La persona que no es capaz de comprender el proceso comunicativo en que consiste el ejercicio del poder político en el seno de un determinado sistema social no puede aportar comunicación alguna ni contribuir a la selección de las que cuentan con un respaldo popular relevante [...]. 
Cuestión distinta, y de mayor complejidad política y técnica, es la de la oportunidad de su exigencia o evaluación, así como, en su caso, la de decidir el momento y la forma de hacerlo. Así, por razones operativas, en la mayoría de los ordenamientos se ha solido presumir su existencia en los mayores de edad, sin que pudiera ponerse en cuestión salvo en supuestos excepcionales y con las debidas garantías - como es el caso, precisamente, de un proceso de modificación de capacidad o internamiento psiquiátrico-, y, al propio tiempo, se ha negado, sin posibilidad de prueba en contrario, a los menores de edad.

Esto significa, en conclusión, que la capacidad electoral para ejercer el sufragio a la que aludía el art. 3 de la LOREG, y que se identifica con la expresión más consolidada de capacidad de autodeterminación política o electoral, es una exigencia legítima para ejercer el sufragio desde el punto de vista de su naturaleza y que no menoscaba el principio de universalidad del sufragio. No afecta a la titularidad del derecho, que permanece inalterada, pero sí constitutiva y justificadamente a su emisión.

\section{NO SE LESIONA EL PRINCIPIO DE IGUALDAD Y NO DISCRIMINACIÓN}

Tampoco compartimos el argumento de que la posibilidad de privar del sufragio a una persona sometida a un proceso de modificación de capacidad o internamiento psiquiátrico, que preveía el art. 3 de la LOREG, vulnere el principio de igualdad y no discriminación reconocido en el art. 14 de la CE, en conexión con la Convención de Nueva York de 2006 (art. 12, en relación con el 5 y el 29), y entrañe una censurable discriminación por razón de

La capacidad de autodeterminación política, fruto de la posibilidad de comprender las diferentes opciones y de discriminar entre ellas las que se consideren preferibles para la orientación de la comunidad, es, pues, una exigencia inherente a la participación y, por este motivo, su ausencia es un límite lógico de este derecho, derivado de la necesidad de preservar su propia idiosincrasia, pues si la intervención política no es expresión de la libertad del individuo, no hay una participación auténtica [...].

[...] no se trataría tanto de un límite en sentido técnico preciso al no ser externo al derecho; es más bien, un elemento de delimitación de ese derecho [...].

Una vez que se ha alcanzado la edad mínima necesaria para el ejercicio del derecho de voto, únicamente se puede excluir de esta forma de participación política a las personas que carezcan de las condiciones intelectivas necesarias para que su intervención sea libre, para que sea expresión de una voluntad con capacidad reflexiva y de discernimiento". 
discapacidad. Frente a lo que se suele alegar por los defensores de esta crítica ${ }^{24}$, no creemos que valorar la capacidad electoral de estas personas sea una actuación en sí misma discriminatoria, ni tampoco que suponga una injerencia desproporcionada en el derecho de voto, siempre que se haga una correcta interpretación de la norma. Veamos separadamente la argumentación.

\section{NO ES UNA MEDIDA ESENCIALMENTE DISCRIMINATORIA}

En relación con el primer elemento de crítica, el de que valorar la capacidad para votar de una persona sometida a un proceso de modificación de capacidad o de internamiento psiquiátrico sea en esencia discriminatorio para las personas con discapacidad, cabe traer a colación varios elementos, de muy distinto tenor.

a) En primer lugar, conviene recordar el significado y exacto alcance del principio de igualdad. Lo primero y más básico que hay que señalar a este respecto es que el principio de igualdad consagrado en el art. 14 de la CE no impide establecer diferencias de trato entre categorías o grupos de personas, sino, más precisa y matizadamente, realizar diferenciaciones que carezcan de una justificación objetiva y razonable; lo censurable desde la perspectiva constitucional de la igualdad no es, pues, que se diferencie, sino que dicha diferencia no esté justificada de acuerdo con criterios o juicios de valor generalmente aceptados ${ }^{25}$.

Además, de manera más específica, hay que precisar que la prohibición de discriminación especial establecida en la segunda parte del art. 14 de la CE y que afecta a una serie de circunstancias personales o sociales («nacimiento, raza, sexo, religión, opinión o cualquier otra condición o circunstancia personal o social»), entre las cuales el Tribunal Constitucional ha incluido la discapacidad ${ }^{26}$, no entraña una prohibición absoluta de realizar un trato dife-

24 En la doctrina, véanse, por ejemplo, Cuenca Gómez (2018: 196-200) y Fishkin (2011: 1353 y ss.). En el ámbito institucional tiene gran interés el Informe del Comité de Derechos de las Personas con Discapacidad de 9 de septiembre de 2013 sobre la Comunicación 4/2011 presentada por varios ciudadanos húngaros (CRPD/C/10/D/4/2011), así como, del mismo Comité, la observación general n. ${ }^{\circ}$ 6, de 2018, sobre la igualdad y la no discriminación consagradas en el art. 5 de la Convención.

25 Así lo señaló muy pronto el Tribunal Constitucional. Véanse al respecto las SSTC 10/1981, de 6 de abril, y 49/1982, de 14 de julio.

26 Sobre este supuesto véase la STC 269/1994, de 3 de octubre. Con posterioridad véanse las SSTC 10/2014, de 27 de enero, 18/2017, de 2 de febrero, y 3/2018, de 22 de enero. En el ámbito de la Unión Europea la situación es más clara, pues la Carta 
renciado con base en uno de esos motivos protegidos, sino, más limitadamente, que dicho trato debe ser objeto de un canon más estricto de justificación ${ }^{27}$. La CE protege, pues, a los ciudadanos frente a la discriminación por una serie de circunstancias o condiciones especialmente arraigadas y marginadoras, como la discapacidad, pero lo hace, no por la vía de la exclusión de toda diferencia de trato basado en una de esas circunstancias, sino por la del rigor en la argumentación y la prueba de dicha diferenciación.

b) En cualquier caso, debe aclararse, como recordó el Tribunal Constitucional, que en el art. 3 de la LOREG no se estaba tratando a las personas con discapacidad como grupo o colectivo ${ }^{28}$; ni en todo, ni en una de sus partes o subgrupos integrantes. No hay que confundir la amplia y genérica categoría de "las personas con discapacidad» —a la que aluden diversas normas tanto nacionales como internacionales_-, ni, más limitadamente, la de las personas con discapacidad intelectual o psíquica —objeto de diversas medidas específicas de acción positiva en nuestro ordenamiento-, con la que integraba el supuesto de hecho del art. 3 de la LOREG, esto es, la de las personas sometidas a un proceso de modificación de capacidad por padecer, con arreglo al Código Civil, una enfermedad o deficiencia persistente que impide a la persona gobernarse por sí misma, o a otro de internamiento psiquiátrico por razón de trastorno psíquico ${ }^{29}$.

Es solo respecto de estas personas sobre las que podía plantearse, en el curso de dicho proceso, entre otras medidas posibles, la privación del ejercicio del sufragio. No se valoraba, por tanto, por la autoridad judicial, la capacidad para votar de las personas con discapacidad en general o de aquellas que adolecían de discapacidad intelectual o psíquica en particular, sino únicamente de quienes padecían una enfermedad o deficiencia que impedía a la persona gobernarse por sí misma, bien de forma persistente, bien de forma temporal por padecer una crisis psíquica, y se encontraban, además, sujetos a un proceso de adopción de medidas.

Y este examen de capacidad electoral es, por otra parte, coherente con la situación de base que padece la persona y con el mecanismo procesal puesto

de derechos fundamentales incluye, en su art. 21, la discapacidad como uno de los factores expresos de protección contra discriminaciones.

27 Así lo dejó claro el Tribunal Constitucional desde su ya lejana Sentencia 81/1982, de 21 de diciembre, FJ segundo. Véanse también la STC 3/1993, de 14 de enero, o la 200/2001, entre otras muchas.

28 ATC 196/2016, de 28 de noviembre, FJ tercero.

29 Sobre las distinciones relevantes en este terreno, véase Fernández de Buján (2011: 86). 
en marcha. Lo que hacía el art. 3 de la LOREG era únicamente concretar para el derecho de sufragio lo que el Código Civil y la Ley de Enjuiciamiento Civil predican con carácter general para las personas que se encuentran en esta particular situación: el examen de su estado para precisar su situación jurídica con arreglo a las concretas circunstancias en que se halla ${ }^{30}$.

c) En tercer lugar, un argumento que va a la raíz misma de la crítica sobre el carácter esencialmente discriminatorio del anterior texto del art. 3 de la LOREG. Se trata de poner de relieve que las personas sometidas a un proceso de modificación de capacidad o de internamiento no son las únicas respecto de las cuales puede cuestionarse la capacidad electoral para ejercer el derecho de sufragio.

La capacidad electoral o de autodeterminación política, de poder formarse y expresar una voluntad consciente y libre, es, como hemos visto en el apartado anterior, un elemento esencial del derecho de sufragio, y, como tal, es exigible siempre a cualquier persona. Lo que ocurre es que, con la mayoría de edad, rige a su favor la presunción de existencia o de concurrencia, pero esta presunción puede ponerse en cuestión en supuestos excepcionales que tengan una sólida justificación y que se rodeen de las debidas garantías. Uno de ellos es, precisamente, el diseñado en el anterior art. 3 de la LOREG, que es independiente de unas elecciones concretas y que tenía lugar con ocasión de un proceso judicial cuyo objeto es la protección de la persona, pero es también perfectamente posible cuestionar la existencia de la capacidad electoral de cualquier persona en el momento mismo de la expresión del sufragio en un proceso electoral concreto si se pone de manifiesto de forma clara la falta de conciencia y voluntad en el elector.

Es esta una posibilidad que siempre ha existido en nuestro ordenamiento, aun sin contar con una regulación específica que la encauce. Las normas de cobertura son, en primer lugar, la Constitución, que, en diversos preceptos (arts. 23.1, 68.1, 69.2, 140), proclama la libertad de voto, y, en segundo lugar, la LOREG, con varios artículos de interés: el 4, que establece el ejercicio personal del sufragio, el 5 , que de modo prohibitivo señala que «nadie puede ser obligado o coaccionado bajo ningún pretexto en el ejercicio de su derecho de sufragio", y el 91.1, que atribuye al presidente de la mesa electoral la

30 Este mecanismo se encuentra desde hace años sujeto a un proceso de crítica y revisión, cuyo exponente fundamental es el Anteproyecto de ley por el que se reforma la legislación civil y procesal en materia de discapacidad, recientemente remitido a las Cortes Generales como proyecto de ley. No obstante, la regulación actual cuenta con el respaldo del Tribunal Supremo, que ha señalado que no es discriminatoria ni contraria a la Convención de 2006. Véase la STS, Sala Civil, 282/2009, de 29 de abril, FF. JJ. quinto y séptimo. 
autoridad exclusiva, dentro del local electoral, para «conservar el orden, asegurar la libertad de los electores y mantener la observancia de la Ley».

Este elenco normativo se ha enriquecido recientemente de manera muy significativa tras la aprobación de la Ley Orgánica 2/2018, de 5 de diciembre, para la modificación de la LOREG, para garantizar el derecho de sufragio de todas las personas con discapacidad. Nos referimos a la introducción en el art. 3.2 de la exigencia expresa de que el sufragio se ejerza "consciente, libre y voluntariamente». Con ella ha quedado más clara la posibilidad de cuestionar la capacidad electoral para votar de cualquier elector.

Ahora bien, el problema, tanto antes de la reforma como ahora, es, como apuntábamos, la falta de mecanismos específicos que ordenen o regulen este cuestionamiento. Ello obliga a acudir a las normas generales que puedan resultar de aplicación más o menos directa ${ }^{31}$, lo cual puede dar lugar a situaciones de gran incertidumbre sobre lo que hacer por parte de los distintos agentes gestores intervinientes en el proceso electoral - fundamentalmente las mesas electorales, pero también los notarios y los funcionarios de Correos-, y, en consecuencia, originar una enorme disparidad de criterios sobre la forma de abordar y resolver la cuestión suscitada.

La Junta Electoral Central ha sido consciente de la situación y ha tratado de ordenar el problema, apuntando determinados criterios interpretativos, en cuya exposición y análisis, sin embargo, no podemos entrar en este momento sin desviarnos de nuestro objeto de estudio ${ }^{32}$. Basta tan solo señalar que la actuación de la Junta ha sido claramente positiva por haber proporcionado seguridad jurídica al proceso electoral, sin perjuicio de que merezca alguna

31 Así, en el caso del voto directo en las mesas electorales, los arts. 91.1 y 99 de la LOREG y concordantes, y en el voto por correo, los arts. 145 y ss. del Reglamento Notarial.

32 La aportación más relevante de la Junta Electoral Central está en la Instrucción 7/2019, de 18 de marzo, sobre aplicación de la modificación de la LOREG llevada a cabo por la Ley Orgánica 2/2018, de 5 de diciembre, en cuyo punto segundo, párrafo 2, se dice: «En el supuesto de que algún miembro de una Mesa Electoral o alguno de los interventores o apoderados adscritos a esa Mesa considere que el voto no es ejercido de forma consciente, libre y voluntaria, lo podrá hacer constar en el acta de la sesión, pero no se impedirá que dicho voto sea introducido en la urna. En esa manifestación de constancia, el acta identificará al elector únicamente por el número de su Documento Nacional de Identidad o, en su caso, por el documento identificativo que aporte». También es de gran interés el Acuerdo de 16 de abril de 2019 de la Junta Electoral Central sobre la actuación que ha de seguir el notario al autorizar poderes electorales, cuyo punto 3 señala: «[...] el juicio notarial de capacidad debe orientarse a la constatación del deseo de votar del elector, así como de designar a una persona que le preste su apoyo en la formulación y recepción de la documentación electoral, sin exigir otras valoraciones que pudieran limitar el ejercicio de su derecho». 
crítica y sea susceptible de revisión y complemento ${ }^{33}$, y que, en todo caso, no compensa la disminución de garantías que supone la supresión de la intervención judicial en la constatación de que el ejercicio del derecho de sufragio no se realiza de forma consciente, libre y voluntaria.

\section{NO ES UNA MEDIDA DESPROPORCIONADA}

No es esto todo lo que cabe apuntar en defensa del ajuste del derogado art. 3 de la LOREG al principio de igualdad. Ello se debe a que no solo se ha criticado de plano, por discriminatoria, la evaluación de la capacidad electoral de las personas sometidas a un proceso de modificación de capacidad o internamiento, sino que también se ha apuntado que dicha evaluación supone, en cualquier caso, una injerencia desproporcionada en el derecho de voto.

Frente a esta segunda crítica son varios los argumentos que utilizar, y que, en conjunto, ponen de manifiesto, a nuestro juicio, la proporcionalidad de este precepto, siempre que se interprete de forma adecuada, es decir, con arreglo a su finalidad y con criterio restrictivo, salvando su censurable falta de precisión ${ }^{34}$. En cualquier caso, conviene mantener en la mayor medida posible la argumentación en un plano general, que trascienda los concretos términos en que estaba redactado el art. 3 y que eran claramente perfectibles, pues la crítica que cuestionamos es también general y aplicable, por tanto, a cualquier norma - esté en el ordenamiento que esté- que permita la restricción del sufragio por falta de autodeterminación de la persona.

Tales argumentos son, sintéticamente expuestos, los siguientes:

a) La finalidad que persigue el art. 3 de la LOREG es de la mayor relevancia en términos constitucionales: de un lado, y de forma principal, proteger la integridad del proceso electoral, que exige en su misma esencia que la expresión del sufragio sea consciente y libre, fruto de la autodeterminación política de la persona, sin sustituciones, ni presiones de terceros, a fin de poder conocer de forma auténtica, sin distorsiones, la voluntad del pueblo, y, de otro lado, de modo secundario, defender el interés de la propia persona afectada, evitando su manipulación y la consiguiente lesión de su dignidad personal ${ }^{35}$.

33 Sobre esta doctrina de la Junta Electoral Central, véanse Gálvez Muñoz (2019: 234 y ss.) y Arnaldo Alcubilla, (2019b: 135 y ss.).

34 Sobre esta deficiencia véanse Gálvez Muñoz (2017: 1081-1082, 1093) y Barrat Esteve (2017: 159).

35 Véanse, fundamentalmente, Presno Linera (2003: 135 y ss.), Cuenca Gómez (2018: 175 y ss.) y Díaz Alabart (2012: 9-10). En la jurisprudencia tiene interés, por integrar 
b) La causa que motivaba la restricción del sufragio que preveía el art. 3.1 de la LOREG es estrictamente la incapacidad electoral o, según los términos literales del precepto, la «incapacidad para ejercer el derecho de sufragio». No es una incapacidad intelectual o psíquica general, ni tampoco se corresponde simplemente con la existencia de una enfermedad o deficiencia que impida a la persona gobernarse por sí misma, sino que es una incapacidad específica para tomar una decisión electoral.

c) El juicio de capacidad que había de realizar el juez exigía, por ello, un examen individualizado de la persona que atendiese a la particular disfuncionalidad que padecía y su repercusión en el sufragio. Es lo lógico y, además, lo había establecido con gran claridad el art. 3.2 de la LOREG, que señalaba en su punto segundo que los jueces o tribunales que entiendan de los procedimientos de incapacitación o internamiento «deberán pronunciarse expresamente sobre la incapacidad para el ejercicio del sufragio y que en el supuesto de que ésta sea apreciada, lo comunicaran al Registro Civil».

d) No existía, por tanto, automatismo alguno entre la puesta en marcha de un proceso de modificación de capacidad o internamiento psiquiátrico, la decisión judicial de introducir efectivamente medidas sobre la persona afectada, tras evaluar la gravedad de sus problemas de autogobernación, y, por último, la adopción de la medida concreta de restricción del sufragio. Era posible, pues, que el proceso concluyese sin que se adoptase medida alguna de carácter restrictivo, así como que se adoptasen medidas de este tipo y que entre ellas no estuviera la privación del ejercicio del sufragio, como también que esta medida sí se decretase junto con otras de otro tipo. Dependía del caso particular. Y así lo recordó el Tribunal Supremo en numerosas ocasiones en los últimos años ${ }^{36}$, aunque los tribunales no hubiesen sido siempre lo rigurosos que debían en la disociación de la restricción del sufragio ${ }^{37}$.

e) La incapacidad electoral o incapacidad para ejercer el sufragio como causa de restricción de este estaba, por otra parte, claramente identificada. Como ya seńalamos anteriormente, la expresión se vincula con el concepto más tradicional de autodeterminación política o electoral, que hace referencia

los dos fines de la norma, la STS, Sala Civil, 181/2016, de 17 de marzo, en donde se seńala que es «una medida dirigida a proteger los intereses del incapaz y el propio interés general de que la participación electoral se realice de forma libre y con un nivel de conocimiento mínimo respecto del hecho de votar y de la decisión adoptada» (FJ 2).

36 Véase, por ejemplo, la STS, Sala Civil, 181/2016, de 17 de marzo, FJ 2.

37 En relación con esta jurisprudencia, véanse García Roca (2007: 183 y ss.), Cuenca Gómez (2018: 187 y ss.) y Martínez-Pujalte (2015: 92 y ss.). 
a la situación de la persona que está en condiciones de formarse una voluntad electoral consciente y libre, de comprender la naturaleza y el efecto de votar y tomar una decisión al respecto. Es la capacidad de poder tomar una decisión de voto de acuerdo con la finalidad del proceso electoral y en las condiciones materiales de personalidad, libertad y voluntariedad requeridas por la propia esencia del derecho de sufragio.

f) La privación del ejercicio del sufragio por la incapacidad electoral de la persona era, por ello, plenamente coherente con la naturaleza de este derecho fundamental, como ya vimos también, pero es necesario reiterar ahora. El derecho de sufragio demanda para su ejercicio, como parte de su núcleo esencial, la capacidad de autodeterminación política; es un elemento básico de su configuración, que queda dentro de su ámbito de delimitación más fundamental.

g) La incapacidad para ejercer el sufragio, no obstante, de acuerdo con una interpretación restrictiva de la norma, propia de las limitaciones de los derechos fundamentales ${ }^{38}$, solo podía declararse en casos excepcionales y extremos en que pudiera encontrarse la persona incursa en un proceso de adopción de medidas, como había ya asumido la jurisprudencia ${ }^{39}$. La interpretación constitucionalmente adecuada de la norma suponía, pues, en materia de evaluación de la capacidad, un estándar de exigencia leve o bajo como criterio general que seguir. La ley no había precisado, sin embargo, la situación o motivos que permitían apreciar tal incapacidad bajo este estándar de mínimos, como hubiera sido deseable y se había propuesto desde distintos sectores $^{40}$ — aunque no es fácil hacerlo-, pero sí cabe señalar que este criterio apunta a supuestos límites, como, entre otros, el estado de inconsciencia o semiinconsciencia, la ausencia de la mínima de capacidad de conocimiento o

38 Vid. la STC 159/1986, de 16 de diciembre, FJ 6.

39 Vid. la STS, Sala Civil, 421/2013, de 24 de junio, FJ 2.

40 En el plano legislativo, véase la enmienda $1 .^{a}$ del Grupo Parlamentario Popular a la Proposición de Ley Orgánica para la modificación de la LOREG para garantizar el derecho de sufragio de todas las personas con discapacidad (Boletín Oficial de las Cortes Generales, Congreso de los Diputados, XII legislatura, serie B, n. ${ }^{\circ}$ 150-4, 16 de marzo de 2018); en el ámbito institucional, la Recomendación del Defensor del Pueblo de 30 de junio de 2016 sobre el derecho de voto de las personas con discapacidad (Queja n. 16008346), la Resolución del Síndic de Greuges de Cataluña de 2015 sobre el ejercicio del derecho de sufragio activo por parte de las personas sobre las que recae una medida judicial de limitación de capacidad (Expediente AO-00091/2015) o el informe del Valedor do Pobo de 2014 sobre los derechos de las personas con discapacidad intelectual en Galicia (p. 46); y en la doctrina, Cuenca Gómez (2012: 84), Pascual Planchuelo (2016: 119-120) o Gálvez Muńoz (2017: 1093). Tras la reforma, véase Pérez Alberdi (2019: 102-103). 
decisión o la pérdida de toda razón o sentido en relación con el acto de votación, como ya había señalado abundante jurisprudencia ${ }^{41}$.

h) En su decisión el juez debía tener en cuenta los diversos intereses y circunstancias concurrentes en el caso y no solo la capacidad abstracta del sujeto para formarse una opinión política y los elevados fines a los que se dirige la medida ${ }^{42}$. Así, había de valorar los efectos que la participación en un proceso electoral puede tener para fomentar la autonomía del sujeto y favorecer su integración social; el entorno familiar y social que tiene el afectado; el hecho cierto de que el derecho de sufragio es intransmisible por su carácter personalísimo y que, por tanto, no cabe ejercerlo por representación, o la posibilidad de paliar o superar la «incapacidad electoral» presente en la persona mediante mecanismos de auxilio o apoyo.

i) Incidiendo en este último punto, es importante advertir que, en sentido estricto, el juez solo podía adoptar la medida de privación del ejercicio del sufragio si no existían en el caso concreto alternativas menos gravosas que permitiesen conseguir una participación libre y consciente del afectado, como serían, precisamente, esas medidas de apoyo. El art. 3 de la LOREG, tal y como había sido interpretado por la jurisprudencia última, como hemos apuntado antes, era una norma de aplicación excepcional y, por tanto, de manera coherente, hay que entender que solo permitía restringir el sufragio cuando no hubiera forma alguna de superar la incapacidad electoral ${ }^{43}$.

j) La decisión judicial se adoptaba tras un concreto proceso rodeado de todas las garantías, de acuerdo con las reglas procesales legalmente previstas: el examen directo por parte del propio juez, el reconocimiento a cargo del médico forense y de otros profesionales que propongan las partes, la audiencia a la persona afectada, sus allegados y el Ministerio Fiscal, y la práctica contradictoria de todas las pruebas a que hubiera lugar ${ }^{44}$. Ni la ley ni la

41 Así, véase, entre otras, la SAP de La Coruña de 11 de marzo de 2015, la SAP de Ciudad Real de 24 de octubre de 2012 y las SSAP de Barcelona de 13 de marzo de 2014, 2 de mayo de 2014, 27 de mayo de 2016, 2 de julio de 2016 y 8 de noviembre de 2018 . Véanse Martínez-Pujalte (2015: 88 y ss.) y Pascual Planchuelo (2016: 117-118).

42 Véase la STS, Sala Civil, 181/2016, de 17 de marzo, FJ 2.

43 Así, la STS, Sala Civil, 421/2013, de 24 de junio, FJ 2.

44 Las reglas no son exactamente las mismas en el proceso de modificación de capacidad y en el de autorización de internamiento psiquiátrico, aunque tomamos como base el primero, dada su mayor importancia práctica. Véanse, en general, los arts. 756 y ss. de la Ley de Enjuiciamiento Civil, así como 199 y ss. del Código Civil. Las peculiaridades del internamiento se encuentran en el art. 763 de la Ley de Enjuiciamiento Civil. 
jurisprudencia habían establecido, sin embargo, un estándar de prueba en este terreno, como hubiera sido deseable, es decir, un método preciso y adecuado para evaluar la capacidad electoral mínima exigible; por ello, los jueces y forenses realizaban la evaluación según su propio criterio, si bien existían protocolos técnicos muy depurados de gran eficacia a su disposición ${ }^{45}$.

k) La resolución que, en su caso, acordase la privación del ejercicio del derecho de sufragio debía contar con una motivación específica y detallada de las concretas circunstancias que cuestionasen la capacidad para el ejercicio del derecho de sufragio y de la ponderación realizada de los intereses en juego, según los criterios específicos de motivación judicial reforzada sentados por el Tribunal Constitucional y el Tribunal Europeo de Derechos Humanos en caso de limitación de derechos, y, en especial, en relación con un grupo especialmente protegido, por vulnerable, como es el de las personas con discapacidad. Es un punto en el que la Fiscalía General del Estado había hecho siempre especial incidencia ${ }^{46}$.

1) La decisión adoptada era, asimismo, recurrible en apelación y, en su caso, casación, y, además, estaba sujeta a las solicitudes de revisión que, en su caso, pudieran presentar el afectado, sus representantes o el Ministerio Fiscal (León Alonso, 2014: 181-183). La cuestión también podía suscitarse con ocasión del informe anual que en caso de modificación de capacidad debía presentar el representante legal ${ }^{47}$.

\section{NO EXISTE INCOMPATIBILIDAD CON EL SISTEMA DE PROTECCIÓN DE LAS PERSONAS CON DISCAPACIDAD}

Nuestra opinión es también crítica con el último argumento empleado contra el anterior art. 3 de la LOREG: el de que resulte incompatible con el

45 Por ejemplo, la herramienta CAT-V (Competence Assessment Tool for Voting). Véanse Balch Hurme y Appelbaum (2007: 931 y ss.), Appelbaum, Bonnie y Karlawish (2005: 2094 y ss.) y Padilla Durán (2016: 111-112). En un plano más general tiene interés el Documento Sitges, que establece criterios básicos para evaluar la capacidad de tomar decisiones de una persona con deterioro cognitivo.

46 Véase la Instrucción de la Fiscalía General del Estado 3/2010, de 29 de noviembre, sobre la necesaria fundamentación individualizada de las medidas de protección o apoyo en los procedimientos sobre determinación de la capacidad de las personas, cuyo punto 5 se refiere a la privación del derecho de sufragio activo de las personas sometidas a estos procedimientos.

47 Véase el art. 269.4 del Código Civil. 
sistema de protección de las personas con discapacidad que establece el art. 49 de la $\mathrm{CE}^{48}$, el cual exige a los poderes públicos realizar una "política de previsión, tratamiento, rehabilitación e integración" y ampararles especialmente «para el disfrute de los derechos que este Título otorga a todos los ciudadanos», en especial si es leído a la luz de la Convención de Derechos de las Personas con Discapacidad de $2006^{49}$, basada en los principios, entre otros, de accesibilidad, participación, inclusión, igualdad y autonomía en la toma de decisiones; en resumen, que restringir el sufragio por razón de incapacidad electoral es todo lo contrario a amparar a las personas con discapacidad en el disfrute de sus derechos o fomentar su participación ${ }^{50}$.

Este argumento, a pesar de su apariencia lógica, no tiene, a nuestro juicio, más consistencia que los anteriores, y no sirve, por tanto, para cuestionar eficazmente la legitimidad de la norma. El sistema español de tratamiento de la discapacidad en su conjunto y, en particular, por lo que aquí interesa, el régimen de modificación de capacidad o internamiento psiquiátrico, tiene, ciertamente, como principal objetivo la protección de la persona afectada — y así lo reconoce expresamente la jurisprudencia ${ }^{51}$ —, pero esto no conlleva, como consecuencia lógica e inevitable, la prohibición absoluta de poder privar del ejercicio del derecho de sufragio por razón de discapacidad intelectual o psíquica en determinados casos.

El razonamiento presenta, ciertamente, debilidades. No se le ha prestado mucha atención, y suele pasar bastante desapercibido, pero el tema tiene interés y merece que le dediquemos unas líneas. Son varios los motivos que aducir:

1) En primer lugar, negamos la mayor. No es cierto que la protección de la persona con discapacidad que ha de informar el sistema de modificación de capacidad o internamiento resulte incompatible con toda medida

48 Sobre este precepto constitucional, véase Álvarez García (2017).

49 Véanse, en especial, los arts. 1 a 3 de la Convención, así como el 5 y el 12.

50 Quien con más ahínco ha defendido este argumento ha sido la Fiscalía General del Estado, que ha señalado que si el fin del proceso es la protección de la persona con discapacidad «difícilmente puede producirse a partir de la eliminación de derechos», y que «resulta harto difícil argumentar» que se priva del derecho de sufragio a la persona con capacidad complementada para evitarle un perjuicio. Véase el recurso de nulidad de actuaciones presentado por la Fiscalía General del Tribunal Supremo el 11 de abril de 2016 contra la Sentencia del Tribunal Supremo de 17 de marzo de 2016. En la doctrina, véanse Díaz Alabart (2012: 13-15), Martínez-Pujalte (2016: 181) y Cuenca Gómez (2018: 196-197).

51 Así, véanse las STS, Sala Civil, de 16 de septiembre de 1999, 14 de julio de 2004 y 29 de abril de 2009. 
restrictiva del ejercicio de derechos fundamentales, pues una cosa es la titularidad de tales derechos, que se tienen con independencia de la situación intelectiva de la persona, y que hay que salvaguardar en todo caso, y otra muy distinta que su ejercicio pueda limitarse en ciertos casos y momentos de la vida en defecto o en combinación con medidas de apoyo, de forma temporal y con sujeción al correspondiente control y posibilidad de revisión.

Restringir no es siempre perjudicar, sino a veces todo lo contrario. Entender otra cosa abocaría, además, a la consideración como discriminatorio del sistema actual de modificación de la capacidad y esto es algo que los tribunales ya han rechazado. Así lo dijo, por ejemplo, el Tribunal Supremo en su trascendental Sentencia de 29 de abril de 2009: «La incapacitación no es una medida discriminatoria porque la situación merecedora de la protección tiene características específicas y propias. Estamos hablando de una persona cuyas facultades intelectivas y volitivas no le permiten ejercer sus derechos como persona porque le impiden autogobernarse $\aleph^{52}$.

2) Tampoco estamos de acuerdo con la extendida idea de que el ejercicio del derecho de sufragio beneficie siempre de manera efectiva a la persona con discapacidad intelectual o psíquica objeto de medidas de protección. En muchos casos será así, pero no siempre. Si la persona no es consciente del significado y trascendencia de este derecho difícilmente tendrá su ejercicio repercusión alguna en su esfera intelectual y sensitiva, más allá de banalizaciones formales vacías de contenido.

Puede suceder incluso lo contrario. Como hemos señalado al hablar de las finalidades de la norma cuestionada, una de ellas, aunque no la principal, es la de proteger a la persona afectada de anomalía mental, evitando su manipulación por terceros y, por tanto, la consiguiente lesión de su dignidad personal. No creemos, en consecuencia, que en estos casos en que una persona se apodera del voto de otra con discapacidad intelectual severa pueda obtener esta beneficio alguno, sino todo lo contrario, su desconsideración como persona al ser utilizada como mero objeto para la consecución de fines ajenos (Gálvez Muñoz, 2009: 82 y ss.; Gómez Garrido, 2018).

3) Finalmente, hay que tener presente que, en cualquier caso, la protección del interés de la persona con discapacidad tampoco es un valor absoluto que deba imponerse de forma inexorable a cualquier otro. Es indudable que el beneficio de la persona afectada es el fin primordial del proceso de modificación de capacidad o internamiento, pero también es cierto que no es el único bien jurídico que considerar, pues también merecen protección los derechos e

52 STS, Sala Civil, 282/2009, de 29 de abril, FJ 7, in fine. Son de gran interés, asimismo, el resto del fundamento 7 y también el 5 . 
intereses de otras personas y los bienes e intereses de la propia sociedad, sin perjuicio de que deba salvaguardarse en todo lo posible el interés de la persona afectada de discapacidad.

Es una cuestión de ponderación, y en ella hay que tener en cuenta un dato de relevancia, como es que el derecho de sufragio no responde exclusivamente a un interés personal o individual del ciudadano, sino también al interés general de la sociedad en el correcto funcionamiento del sistema democrático (Aragón Reyes, 2000: 37 y ss.; Böckenförde, 1993: 104 y ss.; Stern, 1988: 261 y ss.), por lo que su adecuada formación y emisión, consciente y libre, se convierten en un requisito esencial.

Entendemos que el beneficio que el ejercicio de este derecho puede tener para el afectado, como elemento participativo e integrativo, es un elemento que valorar en la ponderación judicial de intereses, pero, en determinados casos, puede ceder ante el interés de la sociedad en que el proceso electoral se desarrolle con integridad, con una expresión consciente y libre del sufragio por parte de quienes participan en él. Le corresponde valorarlo al juez de forma individualizada a la luz de todas las circunstancias concurrentes: cómo afecta a la persona concreta el ejercicio o no del sufragio, qué capacidad de entender y de querer tiene en el plano electoral, qué riesgo de manipulación se detecta en su entorno, y qué apoyos cabe articular para la expresión de un sufragio voluntario, libre y consciente.

Debemos desterrar, por tanto, la idea de que el interés de la persona sometida a modificación de capacidad o internamiento se imponga en todo caso por encima de toda otra consideración y que ha incidido notablemente en la aprobación de la reforma, como ponen de manifiesto los debates parlamentarios. En algún supuesto fue expresada en términos muy expresivos, aunque difícilmente conciliables, a nuestro juicio, con el razonamiento jurídico. Es el caso, por ejemplo, del diputado Ruiz i Carbonell, del Grupo Parlamentario Socialista, quien dijo:

Tengo un amigo, el Sergi, que va en silla de ruedas y hace castells —sí, sí, castells—; le ayudan a subir encima de la piña y él es el que, sobre sus hombros, aguanta un pilar. Encima de él se pone de pie otro casteller y encima, otro más. Le expliqué, mientras tomábamos un refresco, el procedimiento que había que seguir para que se aprobase una iniciativa como esta, y entonces él me preguntó por qué la presentábamos; y yo, muy de manual, le contesté que intentábamos avanzar en una sociedad en la que todos y todas tuviéramos y pudiéramos ejercer los mismos derechos. Me pregunto que para qué. Le contesté y él volvió a preguntar y a repreguntar, hasta que al final le acabé diciendo, como a veces acabo este tipo de conversaciones, una frase que reivindico y que creo que 
hemos de utilizar más porque, por mucho que lo hagamos, no deja de tener sentido. Acabe diciendo: «Porque todos tenemos el mismo derecho a ser felices». Y el Sergi, el casteller de Tarragona que va en silla de ruedas, echó un trago, sonrió y ya no me preguntó más.

Es esa la razón fundamental por la que el Grupo Socialista la defendió en la Asamblea de Madrid y la trae hoy aquí, por lo que los socialistas del Congreso la vamos a votar y haremos todo lo posible para que se tramite cuanto antes, para contribuir a que en nuestro país todos y todas tengamos la oportunidad de poder ejercer todos nuestros derechos, el primero de los cuales es tener la oportunidad de ser feliz. Como decimos en catalán: Aquest es el nostre compromis, este es nuestro compromiso ${ }^{53}$.

Tras estas palabras recoge el diario de sesiones de la Cámara que los diputados aplaudieron. Confirmaban, así, el espíritu de la reforma, que nadie se sienta excluido, sin pararse en nada más. Se olvidaba que el derecho de sufragio no supone solo depositar una papeleta en una urna, sino que tiene un sentido preciso de expresión de la voluntad electoral consciente y libre de la ciudadanía y que cumple una alta función en la construcción y pervivencia del sistema democrático, que no cabe banalizar.

\section{BIBLIOGRAFÍA}

Aláez Corral, B. (2006). Nacionalidad, ciudadanía y democracia: ¿a quién pertenece la Constitución de 1978? Madrid: Centro de Estudios Políticos y Constitucionales.

Álvarez García, H. (2017). La tutela constitucional de las personas con discapacidad. Revista de Derecho Político, 100, 1027-1055. Disponible en: https://doi.org/10.5944/ rdp.100.2017.20725.

53 Véase Diario de Sesiones del Congreso de los Diputados, Pleno y Diputación Permanente, XII legislatura, n. ${ }^{\circ} 87,7$ de noviembre de 2017, p. 16. Es el caso también del senador De Lara Guerrero, del mismo grupo político, en la que fue la última intervención de la reforma: «Hemos presenciado situaciones de personas con discapacidad llorando en las puertas de un colegio electoral porque no podían votar, porque se les prohibía votar, cuando ellos ya tenían decidido a quién votar y por qué votar. Sus razones son tan respetables y tan inescrutables como las de los que sí podemos votar. A esas personas que no habían sido llamadas al convite democrático hoy también les estamos ofreciendo felicidad. Nada más y nada menos. Por ello, todos los grupos políticos deberíamos estar orgullosos» (Diario de Sesiones del Senado, Pleno, n. ${ }^{\circ}$ 90, 21 de noviembre de 2018, pp. 174-175). 
Appelbaum, P. S., Bonnie, R. J. y Karlawish, J. H. (2005). The capacity to vote of persons with Alzheimer's disease. American Journal of Psychiatry, 162, 11, 2094-2100. Disponible en: https://doi.org/10.1176/appi.ajp.162.11.2094.

Aragón Reyes, M. (2000). Democracia y representación. Dimensiones subjetiva y objetiva del derecho de sufragio. Corts. Anuario de Derecho Parlamentario, 9, 37-60.

Arnaldo Alcubilla, E. (2019a). La reforma del art. 3 de la LOREG: el reconocimiento del derecho de sufragio para todas las personas con la capacidad modificada. El consultor de los Ayuntamientos y los Juzgados, 2, 28-39.

(2019b). El reconocimiento del derecho de sufragio de las personas incapacitadas judicialmente. En J. Guillen (coord.). Libro Homenaje a José Manuel Sala Arquer (pp. 79-143). Madrid: Congreso de los Diputados.

Azpitarte Sánchez, M. (2002). La dimensión constitucional del procedimiento electoral. Teoria y Realidad Constitucional, 10-11, 425-443. Disponible en: https://oi. org/10.5944/trc.10-11.2002.6578.

Balch Hurme, S. y Appelbaum, P. (2007). Defining and Assessing Capacity to Vote: The Effect of Mental Impairment on the Rights of Voters. McGeorge Law Review, 38, 931-978.

Barrat Esteve, J. (2017). Discapacitados mentales y participación política: el derecho de sufragio. En G. Escobar Roca (ed.). Ombudsman y colectivos en situación de vulnerabilidad. Actas del III Congreso Internacional del PRADPI (pp. 151-166). Valencia: Tirant lo Blanch.

Beckman, L. (2009). The Frontiers of Democracy. The Right to vote and its limits. New York: Palgrave-McMillan. Disponible en: https://doi.org/10.1057/9780230244962.

Böckenförde, E.-W. (1993). Escritos de derechos fundamentales. Baden-Baden: Nomos Verlagsgesellschaft.

Cuenca Gómez, P. (2012). El sistema de apoyo en la toma de decisiones desde la Convención Internacional sobre Derechos de las Personas con Discapacidad: principios generales, aspectos centrales e implementación en la legislación española. Revista Electrónica del Departamento de Derecho de la Universidad de La Rioja, 10, 61-94. Disponible en: https://doi.org/10.18172/redur.4104.

- (2018). El derecho de voto de las personas con discapacidad intelectual y psicosocial. La adaptación de la legislación electoral española a la Convención Internacional de Derechos de las Personas con Discapacidad. Derechos y Libertades, 38, 171-202. Disponible en: https://doi.org/10.18543/aahdh-11-2013pp17-40.

Díaz Alabart, S. (2012). El derecho de sufragio de las personas con discapacidad. La visión civilista. Revista de Derecho Privado, 1, 3-24.

Fernández de Buján, A. (2011). Capacidad. Discapacidad. Incapacidad. Incapacitación. Revista de Derecho de la UNED, 9, 83-92. Disponible en: https://doi.org/10.5944/ rduned.9.2011.11069.

Fernández Esquer, C. (2019). La tramitación parlamentaria de la reforma del sufragio de las personas con discapacidad: elementos para un debate. IgualdadES, 1, 219-234. Disponible en: https://doi.org/10.18042/cepc/IgdES.1.08.

Fishkin, J. (2011). Equal Citizenship and the Individual Right to Vote. Indiana Law Journal, 86, 1289-1360. 
Gálvez Muñoz, L. A. (2009). El derecho de voto de los discapacitados y otras personas vulnerables. Teoría, critica y práctica. Valencia: Tirant lo Blanch.

- (2014). El derecho de sufragio en el siglo xx. Derechos y Libertades, 31, 163-189.

- (2017). El régimen de la participación electoral de las personas con discapacidad en los cuarenta años de democracia. Revista de Derecho Político, 100, 1057-1096. Disponible en: https://doi.org/10.5944/rdp.100.2017.20726.

- (2019). La exigencia de que el sufragio se ejerza "consciente, libre y voluntariamente» del nuevo artículo 3.2 de la Ley Orgánica del Régimen Electoral General. Dudas interpretativas y pautas de aplicación. IgualdadES, 1, 235-250. Disponible en: https://doi. org/10.18042/cepc/IgdES.1.09.

García Roca, J. (2007). Declaración de incapacidad y privación del derecho de sufragio activo y pasivo. En I. Serrano García (coord.). La protección jurídica del discapacitado. II Congreso Regional (pp. 171-189). Valencia: Tirant lo Blanch.

Gómez Garrido, L. M. a (2018). El derecho de sufragio activo de las personas con discapacidad intelectual. Almacén de derecho [blog], 28-12-2018. Disponible en: https://bit. ly/2LlaE68.

Kelsen, H. (1934). Esencia y valor de la democracia. Barcelona: Labor.

León Alonso, M. (2014). Los derechos de participación política de las personas con discapacidad: el derecho al voto. Revista Europea de Derechos Fundamentales, 24, 167-193.

Martínez-Pujalte, A.-L. (2015). Derechos fundamentales y discapacidad. Madrid: Cinca. (2016). Derechos en conflicto, conflicto de derechos: principales fricciones entre la Convención Internacional sobre los Derechos de las Personas con Discapacidad y la legislación nacional española. En L. C. Pérez Bueno y R. de Lorenzo García (dirs.). La Convención Internacional sobre los Derechos de las Personas con Discapacidad: 20062016 una década de vigencia (pp. 149-186). Madrid: Cinca.

Padilla Durán, D. A. (2016). Interdicción por discapacidad mental y derecho al sufragio activo. Revista de Derecho Electoral, 22, 99-118.

Pascual Planchuelo, V. C. (2016). El derecho de voto de las personas con discapacidad y, en especial, de las personas con discapacidad psíquica o intelectual en Derecho Internacional. Su recepción en Espańa. Revista Española de Discapacidad, 4 (1), 101-122. Disponible en: https://doi.org/10.5569/2340-5104.04.02.06.

Pérez Alberdi, M. ${ }^{a}$ R. (2013). El derecho fundamental a participar en los asuntos públicos. Madrid: Congreso de los Diputados.

(2019). Los derechos de participación política de las personas con discapacidad. Lex Social. Revista Jurídica de los Derechos Sociales, 9, 1, 83-107. Disponible en: https://doi. org/10.46661/lexsocial.3973.

Presno Linera, M. Á. (2003). El derecho de voto. Madrid: Tecnos.

Rivas Vañó, A. (2018). Discapacidad intelectual y derecho al sufragio: la inacción del Tribunal Constitucional español. En M. ${ }^{\mathrm{a}}$ V. Caruso Fontán y M. ${ }^{\mathrm{a}}$ R. Pérez Alberdi (dirs.). Diálogos judiciales en el sistema europeo de protección de derechos: una mirada multidisciplinar (pp. 273-289). Valencia: Tirant lo Blanch.

Solozábal Echavarría, J. J. (2004). La actuación efectiva del proceso electoral y sus posibilidades. Revista Española de Derecho Constitucional, 70, 127-160. 
Stern, K. (1988). El sistema de los derechos fundamentales en la República Federal de Alemania. Revista del Centro de Estudios Constitucionales, 1, 261-277.

Vyhnánek, L. (2010). Mental disability and the right to vote in Europe: a few notes on the recent development. International Journal of Disability Studies, 7(1), 113-133. 